\title{
IMPLEMENTASI RANCANGAN LAN DAN INSTALASI SLIM STUDI KASUS : PERPUSTAKAAN FAKULTAS ADAB DAN HUMANIORA UIN IMAM BONJOL PADANG
}

\author{
Mega Orina Fitri \\ Prodi D3 Ilmu Perpustakaan UIN Imam Bonjol Padang \\ E-mail: orina_95@yahoo.com
}

\begin{abstract}
Abstrak: Saat ini perpustakaan di perguruan tinggi umumnya sudah memiliki fasilitas perangkat keras berupa beberapa set komputer dan peripheral-nya untuk otomasi perpustakaan. Tetapi masih banyak yang belum menerapkan konsep Local Area Network (LAN) untuk menghubungkan berbagai perangkat keras tersebut, sehingga layanan bagi pemustaka belum maksimal. Karena itu pada tulisan ini diberikan bentuk rancangan LAN dan implementasinya, sekaligus cara melakukan instalasi SLiMS (Senayan Library Management System) sebagai sistem pengaturan / manajemen perpustakaan, dengan studi kasus perancangan LAN dan instalasi SLiMS pada Perpustakaan Fakultas Adab dan Humaniora (FAH) Universitas Islam Negeri (UIN) Imam Bonjol Padang. Hasil akhir penelitian ini adalah terbentuknya suatu koneksi LAN dan digunakannya SLiMS pada Perpustakaan FAH UIN Imam Bonjol Padang, yang dapat meningkatkan efisiensi waktu kegiatan perpustakaan (library housekeeping).
\end{abstract}

Kata Kunci: LAN, Local Area Network, Senayan Library Management System, SLiMS, Perpustakaan.

\section{PENDAHULUAN}

$\mathrm{S}$ etiap perguruan tinggi sudah selayaknya memiliki minimal satu atau lebih perpustakaan sebagai pelaksanaan dari Tri Darma Perguruan Tinggi. Perpustakaan di perguruan tinggi dapat berupa perpustakaan pusat, perpustakaan fakultas ataupun perpustakaan jurusan. Untuk memaksimalkan pelayanan di perpustakaan, saat ini sudah banyak perguruan tinggi yang melakukan otomasi (komputerisasi) perpustakaan dengan menyediakan fasilitas komputer dan perangkat tambahan (peripheral)-nya.

Kenyataannya, walaupun sudah memiliki banyak perangkat (komputer dan peripheral-nya) untuk melakukan otomasi perpustakaan, ternyata masih banyak perpustakaan perguruan tinggi yang belum membangun LAN (Local Area Network). Berbagai perangkat komputer tersebut belum terintegrasi satu sama lain sehingga mengurangi efisiensi pelayanan di perpustakaan tersebut.

LAN di perpustakaan dapat berfungsi untuk menangani kegiatan perpustakaan (library housekeeping). Kegiatan tersebut diantaranya input data, membuat bibliografi, membuat dan mencetak katalog, menangani administrasi perpustakaan dan sirkulasi (kegiatan peminjaman dan pengembalian koleksi), menyediakan penelusuran melalui OPAC (Online Public Access Catalogue), membuat statistik pengunjung, dll. (Ariawan, 2010). 
Perangkat lunak yang dapat digunakan untuk menangani berbagai kegiatan perpustakaan tersebut adalah SLiMS (Senayan Library Management Systems). SLiMS merupakan suatu sistem perangkat lunak berbasis web yang dapat digunakan untuk mengelola manajemen perpustakaan. SLiMS dirancang sesuai dengan standar pengelolaan koleksi perpustakaan, misalkan standar pendeskripsian katalog berdasarkan ISBD yang juga sesuai dengan aturan pengatalogan Anglo-American Cataloging Rules yang umum dipakai di seluruh dunia. SLiMS dapat diperoleh secara gratis dan bersifat Open Source. (Fitri, 2018).

Universitas Islam Negeri (UIN) Imam Bonjol Padang adalah salah satu contoh perguruan tinggi yang memiliki beberapa perpustakaan, yaitu satu perpustakaan pusat dan beberapa perpustakaan fakultas. Salah satu perpustakaan yang ada di UIN Imam Bonjol Padang adalah Perpustakaan Fakultas Adab dan Humaniora. Perpustakaan ini terdiri dari 2 ruangan yang cukup besar yang masing-masingnya berukuran sekitar 25 dan 30 meter persegi. Setiap ruangan dikelola oleh seorang staf. Jumlah koleksi perpustakaan sebanyak 4.298 judul buku, 6.842 eksemplar jurnal dan 1.442 judul skripsi dan tugas akhir. Selain itu perpustakaan ini memiliki 4 set komputer, 1 printer, dan 2 bar-code scanner. Perpustakaan ini melayani lebih dari seribu mahasiswa aktif di Fakultas Adab dan Humaniora UIN Imam Bonjol Padang, dan juga mahasiswa dari fakultas lain, beserta dosen-dosennya.

Jika dilihat dari kondisi dan fasilitas yang ada di perpustakaan Fakultas Adab dan Humaniroa UIN Imam Bonjol Padang, maka sudah seharusnya dibangun suatu jaringan lokal yang akan mengintegrasikan berbagai perangkat komputer dan printer sehingga dapat meningkatkan efisiensi waktu untuk kegiatan perpustakaan (library housekeeping).

Berdasakan uraian di atas, maka perlu dibuat rancangan LAN dan dilakukan implementasinya untuk mengintegrasikan berbagai perangkat komputer dan peripheralnya, sekaligus dilakukan instalasi SLiMS. Dalam hal ini studi kasus yang diangkat koneksi LAN di Perpustakaan Fakultas Adab dan Humaniora UIN Imam Bonjol Padang. Perancangan ini. Hasil rancangan ini nantinya dapat juga diterapkan di perpustakaan lain dengan kondisi dan fasilitas yang tidak berbeda jauh dengan kondisi dan fasilitas di Perpustakaan Fakultas Adab dan Humaniora UIN Imam Bonjol Padang.

\section{METODE PENELITIAN}

\section{A. Jenis dan Lokasi Penelitian}

Dalam penelitian ini penulis menggunakan jenis penelitian kualitatif yang bersifat pengembangan produk yang digunakan dalam bidang pendidikan. Sedangkan lokasi penelitian adalah di Perpustakaan Fakultas Adab dan Humaniora (FAH) Universitas Islam Negeri (UIN) Imam Bonjol Padang. Perpustakaan ini beralamat di Kampus II UIN Imam Bonjol, Jl. Prof. Mahmud Yunus, Lubuk Lintah Padang, Sumatera Barat.

\section{B. Teknik dan Instrumen Pengumpulan Data}

Dalam melakukan penelitian ini, digunakan teknik/metode observasi, wawancara dan dokumentasi dalam mengumpulkan data. Instrumen yang digunakan panduan observasi, pedoman wawancara dan daftar pertanyaan, serta daftar checklist dan tabel. 


\section{Jenis Data}

\section{Data Primer}

Data primer diperoleh langsung dari hasil observasi di Perpustakaan Fakultas Adab dan Humaniora UIN Imam Bonjol Padang. Selain itu data primer juga diperoleh dari hasil wawancara terhadap staf/pustakawan dan pemustaka serta hasil dokumentasi.

\section{Data Sekunder}

Data sekunder pada penelitian ini berasal dari berbagai referensi seperti yang terdapat pada daftar pustaka. Data sekunder digunakan sebagai tambahan pengetahuan dan menjadi referensi dalam penelitian.

\section{KONSEP DAN PERANCANGAN}

\section{A. Perancangan LAN}

Perancangan LAN diperlukan agar dapat dioperasikan secara maksimal, memberikan kenyamanan dan keamanan bagi pustakawan/staf, dan pemustaka. Berapa pertimbangan yang dalam perancangan LAN : aman, nyaman, rapi, dalam unit atau dekat dengan pengguna, jumlah terminal cukup, dan adanya system administrator (Yani, 2015).

Menurut Tanenbaum (2000), jaringan komputer merupakan kumpulan pernagkat keras dan lunak dalam suatu sistem yang memiliki aturan tertentu untuk mengatur komunikasi semua anggotanya. Tujuan dari jaringan komputer adalah untuk berbagi sumber daya (printer, unit sistem / PC, basis data, dll), komunikasi (e-mail, chatting, dll) dan akses informasi (web browsing).

Arsitektur jaringan komputer dapat dibedakan berdasarkan skala, topologi, fungsi, dan media. Berdasarkan skala ada 5 jaringan komputer yaitu LAN (Local Area Network), MAN (Metropolitan Area Network), WAN (Wide Area Network), intranet, dan internet.(Fitri, 2018). Berdasarkan topologi, terdapat topologi Bus, Ring, Star, Fully Connected, dan Mesh. Berdasarkan fungsi jaringan komputer ada 2 yaitu Peer-to-Peer (hubungan langsung antara 2 komputer dan kedudukan kedua komputer sama) dan Client-Server (ada komputer sebagai Server / penyedia sumber daya dan ada yang sebagai Client / pengguna sumber daya). Sedangkan jika berdasarkan media komunikasi, terdapat jaringan komputer yang menggunakan kabel (wireline) dan jaringan komputer wireless (nirkabel).

Untuk studi kasus perpustakaan Fakultas Adab dan Humaniora UIN Imam Bonjol Padang, akan dipilih arsitektur sebagai berikut. Mengingat luas area perpustakaan dan ketersedian sumber daya, maka yang lebih cocok dibuat adalan LAN yang menggunakan topolologi Star dengan hubungan antar komputernya adalah ClientServer melalui kabel (wireline). Server yang akan digunakan adalah jenis NonDedicated Server, yaitu server yang juga bisa berfungsi sebagai workstation. Sistem Operasi yang digunakan adalah Windows 7. Kabel yang digunakan adalah kabel UTP/STP sesuai dengan kebutuhan dan ketersediaan dana.

\section{B. Pembuatan Kabel Straight}

Seperti diketahui sebelumnya berdasarkan hasil observasi dan wawancara, perangkat keras yang sudah ada di perpustakaaan dan siap untuk dihubungkan dalam satu jaringan adalah sebagai berikut: 
1. Empat buah PC (Personal Computer) / set komputer dengan spesifikasi masingmasing : Prosesor Core 2 Duo, RAM 2 GB, dan Harddisk 500GB. Satu PC (set komputer) akan menjadi non-dedicated server, dan 3 PC lainnya menjadi client.

2. Satu buah printer.

Untuk membangun LAN sesuai pilihan arsitektur jaringan di atas, diperlukan perangkat tambahan berupa switch serta kabel UTP/STP. Kabel ini nanti akan menghubungkan antara komputer dan printer melalui suatu switch. Jenis kabel UTP/STP yang diperlukan adalah kabel straight. Sedangkan peralatan yang diperlukan untuk membuat kabel straight adalah : kabel UTP/STP dengan panjang secukupnya, RJ-45, crimping tool dan LAN-cable tester. Gambar 2 di bawah ini memperlihatkan peralatan yang dibutuhkan untuk pembuatan kabel straight.

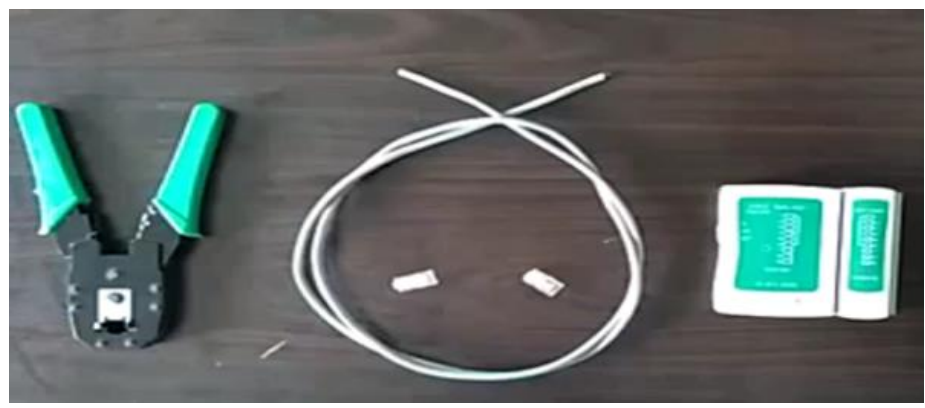

Gambar 1. Peralatan untuk Membuat Kabel Straight

\section{Koneksi LAN dengan Menggunakan Switch}

Berdasarkan data kondisi dan fasilitas perangkat keras yang tersedia di perpustakaan Fakultas Adab dan Humaniora UIN Imam Bonjol Padang, maka dibuat rancangan LAN dengan melakukan penambahan perangkat switch. Adapun rancangan secara umum dapat dilihat seperti Gambar 2 di bawah ini.

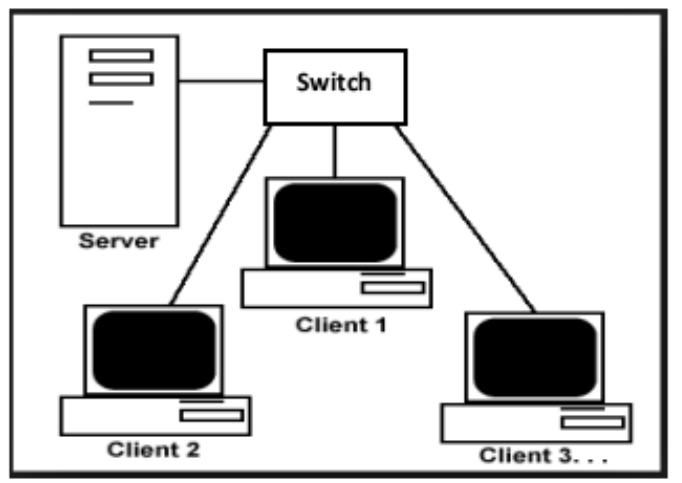

Gambar 2. Rancangan LAN Client-Server dengan Switch

\section{Instalasi SLiMS di Server}

Selanjutnya, setelah selesai dilakukan koneksi LAN, lakukan instalasi Sistem Operasi Windows 7 dan aplikasi-aplikasi pendukung di setiap komputer. Setelah itu dilakukan instalasi SLiMS di komputer server. Aplikasi SLiMS digunakan untuk mengelola berbagai kegiatan perpustakaan (Library Housekeeping). Komputer client dapat mengakses SLiMS yang sudah diinstal di server melalui web browser. Versi SLiMS yang digunakan adalah SLiMS 8 Akasia. 


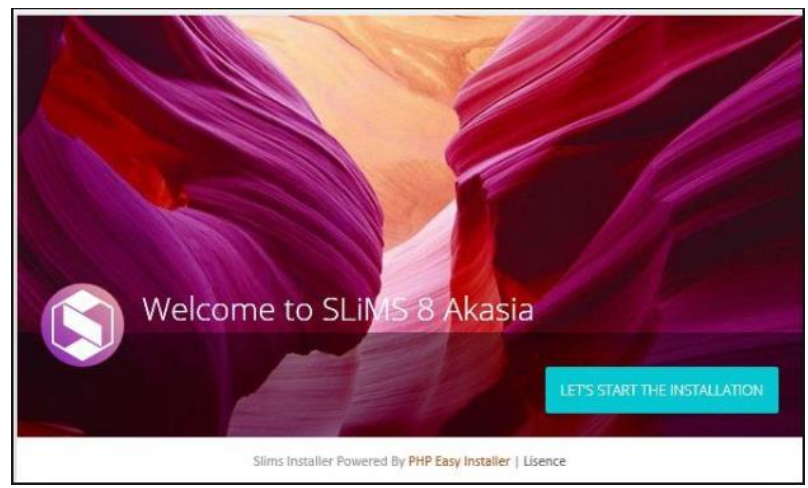

Gambar 3. SLiMS 8 Akasia

\section{HASIL DAN PEMBAHASAN}

Langkah awal dalam perancangan LAN adalah pembuatan kabel straight UTP/STP. Adapun urutan warna kabelnya dapat dilihat pada Tabel 1 berikut ini.

Tabel 1. Urutan Warna Kabel Straight

\begin{tabular}{ccc}
\hline Terminal 1 & Warna & Terminal 2 \\
\hline 1 & White/Orange & 3 \\
\hline 2 & Orange & 6 \\
\hline 3 & White/Green & 1 \\
\hline 4 & Blue & 5 \\
\hline 5 & White/Blue & 2 \\
\hline 6 & Green & 7 \\
\hline 7 & White/Brown & 8 \\
\hline 8 & Brown &
\end{tabular}

Cara pembuatan kabel straight selengkapnya dapat dilihat di link youtube berikut ini : https://www.youtube.com/watch?v=TXfYnGlp9FE.

Setelah selesai membuat kabel straight, lakukan rancangan awal LAN seperti gambar di bawah ini.

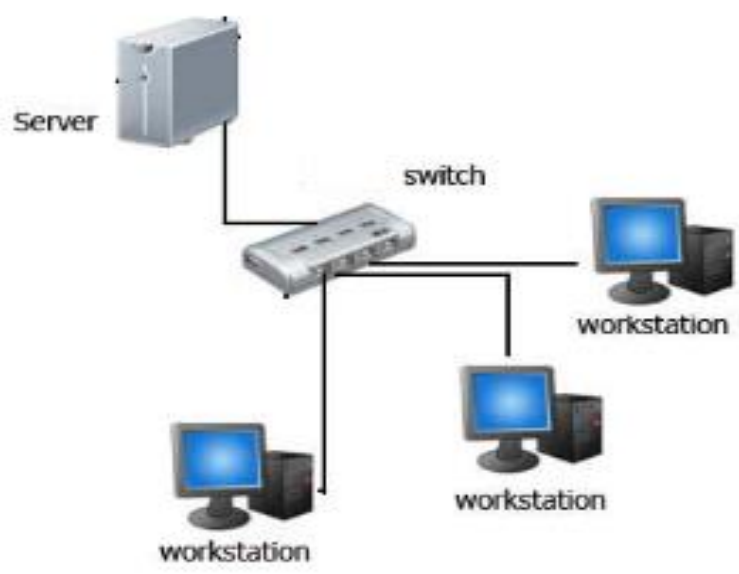

Gambar 4. Rancangan LAN di Perpustakaan FAH UIN Imam Bonjol Padang 
Implementasi LAN dilakukan sesuai dengan langkah-langkah berikut ini.

1. Hubungkan keempat komputer (A sebagai server serta B, C, dan D sebagai client) dengan menggunakan switch dan kabel straight.

2. Masukan IP address di setiap komputer (A,B,C dan D). Misalkan komputer A 192.168.1.24, Komputer B 192.168.1.25, Komputer C 192.168.1.26 dan komputer C 192.168.1.27

Contoh untuk komputer A :

- Pilih Control Panel kemudian pilih Network Adapter dan pilih Local Area Connections. Klik $2 \mathrm{X}$ bagian Local Area Connections kemudian pilih Internet, Protocol (TCP/IP) kemudian Properties.

- Isikan alamat di Komputer A dengan IP 192.168.1.24 dengan subnetmask 255.255.255.0

- Lakukan hal yang sama untuk komputer B,C, dan D.

3. Melalui jendela console CMD, dari komputer A ping ke komputer B , C dan D. Jika terhubung, maka akan mundul di layar : Reply From.... TTL $=128 \ldots$, dan di Windows Eksplorer, pada menu kiri yaitu Network, akan terlihat bahwa komputer $\mathrm{A}, \mathrm{B}, \mathrm{C}$ dan $\mathrm{D}$ sudah saling terkoneksi.

Untuk melakukan koneksi printer dengan jaringan, dapat diikuti langkahlangkah dalam link https://www.youtube.com/watch?v=ijBrAsxdhyw\&t=48s ini.

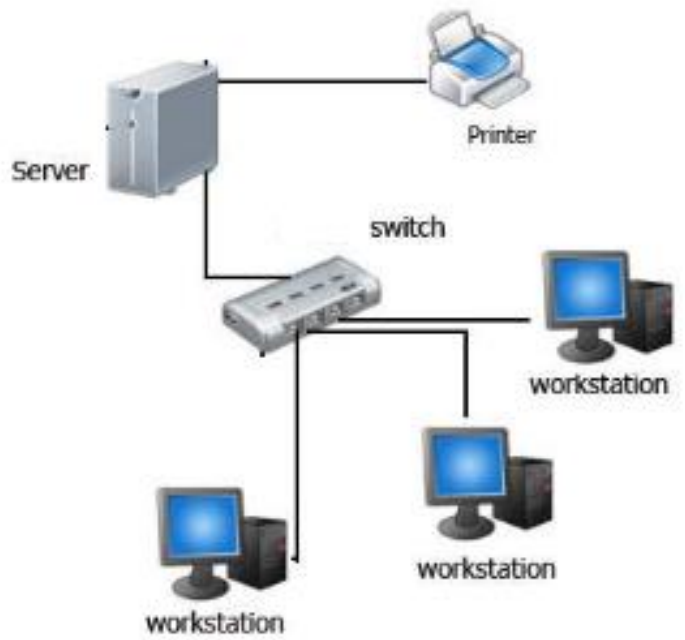

Gambar 5. Rancangan LAN dengan Sharing Printer pada Server di Perpustakaan FAH UIN Imam Bonjol Padang

Setelah semua perangkat keras terkoneksi dan operating sistem telah ada di setiap komputer, maka langkah selanjutnya adalah melakukan instalasi SLiMS di komputer server. Adapun langkah-langkah instalasi SLiMS 8 Akasia dapat dilihat pada link https://www.youtube.com/watch?v=mibIU6d-Cbg\&t=174s ini.

Langkah terakhir adalah melakukan uji coba sistem oleh pustakawan/staf dan pemustaka sebagai pengguna. Selanjutnya disebarkan angket kepuasan terhadapa 30 pengguna terhadap sistem baru yang digunakan. Hasilnya, 90\% pengguna menyatakan Sangat Setuju (Sangat Puas) dan sisanya 10\% pengguna menyatakan Setuju (Puas) 
terhadap rancangan dan implementasi sistem ini karena terbukti dapat meningkatkan efisiensi waktu kegiatan perpustakaan.

\section{KESIMPULAN}

Berdasarkan pada penelitian dan hasil pengujian, maka dapat disimpulkan bahwa hasil implementasi rancangan LAN dan instalasi SLiMS pada Perpustakaan Fakultas Adab dan Humaniora UIN Imam Bonjol Padang sudah dapat berfungsi dengan baik untuk mempercepat pelayanan. Pengujian yang dilakukan oleh pustakawan/staf dan pemustaka dalam melakukan kegiatan perpustaan menunjukkan hasil yang cukup memuaskan. Hal ini dapat disimpulkan berdasarkan angket yang disebar ke psutakawan/staf dan pemustaka sebagai user target, dimana dari 30 orang, 90\% menyatakan Sangat Setuju dan 10\% Setuju akan keberadaaan dan manfaat koneksi LAN berikut aplikasi SLiMS yang telah diterapkan perpustakaan tersebut, karena dapat meningkatkan efisiensi waktu kegiatan perpustakaan (library housekeeping) dibanding sebelumnya.

\section{DAFTAR PUSTAKA}

Ariawan, Putu Rusdi. (2010). Teknologi Informasi dalam Sistem Jaringan Perpustakaan Perguruan Tinggi (Perpustakaan Elektronik). Denpasar: Fakultas Teknik Universitas Udayana. Diakses pada https://www.scribd.com/doc/34769752/Teknologi-Informasi-Dalam-Sistem-JaringanPerpustakaan-Perguruan-Tinggi

Devil. (2010). Perbedaan Antara Server-Client dengan Topologi Jaringan. Diakses pada http://devilzrainbow.blogspot.com/2010/05/perbedaan-antara-server-client-dengan.html

Fitri, Mega Orina. (2018). Handout Mata Kuliah Komputer dan Jaringan. Padang: Fakultas Adab dan Humaniora UIN Imam Bonjol Padang.

Ridwan, Slamet. (2008). Arsitektur Client Server. Diakses pada https://slametridwan.wordpress.com/arsitektur-client-server/

Saputra, Dwi Fajar. (2015). Diakses pada https://www.slideshare.net/DwiFajarsaputra/perangkat-untukmembangun-jaringan-lan-di-perpustakaan

Tanenbaum, Andrew S. (2000). Jaringan Komputer (Computer Network). Jakarta: Prenhallindo.

Yani, Edward. (2015). Handout Pertemuan IV Topik : Jaringan Komputer Perpustakaan. Diakses pada https://slideplayer.info/slide/4103552/ 